\title{
Clinical Trials Third Party Curriculum Vitae
}

National Cancer Institute

\section{Source}

National Cancer Institute. Clinical Trials Third Party Curriculum Vitae. NCI Thesaurus.

Code C125440.

A summary of educational and work experience qualifications of third parties in a clinical trial, such as vendors. 